\title{
A Aprendizagem Baseada em Equipes: ferramenta de ensino potente para a educação e prática interprofissional
}

Lucas Cardoso dos Santos, Renata Maria Zanardo Romanholi, Alice Yamashita Prearo, Janete Pessuto Simonetti

\section{Resumo}

A Aprendizagem Baseada em Equipes: ferramenta de ensino potente para a educação e prática interprofissional Introdução A implantação e o desenvolvimento do Sistema Único de Saúde (SUS) introduziram novos desafios à formação das profissões da saúde em nosso país, principalmente no que tange preparar profissionais que trabalhem no SUS de forma coerente com seus pressupostos ético-políticos, que respondam à complexidade dos problemas de saúde e ofereçam uma atenção com qualidade e segurança aos seus usuários. Nesse sentido a educação interprofissional tem sido apontada como uma ferramenta capaz de promover mudanças nos cenários de ensino, buscando práticas eficientes para o enfrentamento dos problemas sociais e de saúde e por isso tem sido utilizada com o intuito de buscar mudanças na formação profissional e uma melhor integração do ensino com os serviços de saúde, e, também, de melhorar as relações entre os profissionais de diferentes profissões de saúde. Uma estratégia para promover a educação interprofissional, sem dúvida é trabalhar com metodologias de ensino que valorizem os conhecimentos prévios dos alunos, tendo em vista a busca da aprendizagem significativa. Nessa conjuntura, tem-se como objetivo relatar a experiência no uso da Aprendizagem Baseada em Equipes (ABE) como ferramenta para discutir a educação e prática interprofissional em uma disciplina dos currículos da medicina e enfermagem da Faculdade de Medicina de Botucatu (FMB)/UNESP. O presente relato se debruçou sobre o universo da disciplina Interação-Universidade-Serviço-Comunidade (IUSC) desenvolvida na FMB que é orientada pela integralidade e humanização do cuidado no contexto da Atenção Primária à Saúde e pelo o uso de metodologias de ensino que transpõem o ensino tradicional, tendo a educação interprofissional como base do processo de ensino-aprendizagem para promover uma futura prática colaborativa entre os profissionais de saúde. Essa disciplina é oferecida aos primeiros (IUSC I) e segundos anos (IUSC II) dos cursos de enfermagem e medicina e apenas ao terceiro ano do curso médico (IUSC III). Os graduandos em questão somam cerca de 120 alunos (a cada ano): 30 da enfermagem e 90 da medicina e para o desenvolvimento das atividades são divididos em grupos mistos (alunos dos dois cursos), sob a supervisão de um professor-tutor. O professor-tutor pode ser docente ou não, da área da saúde ou não, da medicina/enfermagem ou não. $\mathrm{O}$ que se busca é estimular a troca de experiências entre as diversas áreas do conhecimento, por meio de uma prática interdisciplinar. Aqui vale destacar a parceria firmada entre Secretaria Municipal da Saúde de Botucatu e FMB que permite que parte dos profissionais dos serviços de saúde possam atuar como professores-tutores nas disciplinas. Destacase que os cenários de prática dessas disciplinas são as Unidades Básicas de Saúde e as Unidades Saúde da Família do município de Botucatu e seus respectivos territórios de abrangência. E que os sujeitos envolvidos nessa experiência aqui relatada são os discentes e professores-tutores da IUSC II. Outro ponto a ser considerado é que esses professores têm em sua agenda de compromissos com as disciplinas reuniões periódicas nas quais são trazidos discussões e momentos de estudos relacionados a temas que permeiam todo o processo de ensino-aprendizagem das mesmas. Nesse sentido, com o intuito de oportunizar uma aproximação dos discentes e também professor-tutores com o referencial teórico da prática da educação interprofissional, foi programada uma atividade que se utilizou da $\mathrm{ABE}$, por essa permitir o aprofundamento de conhecimentos e a reflexão sobre o 
ISSN 2179-6750

tema no contexto da formação e prática em saúde. A ABE tem três etapas no seu desenvolvimento: preparação (pré-classe), garantia de preparo que ocorre na classe de aula (teste individual, teste em equipe, apelação e feedback do professor) e aplicação do conceito, também realizado em classe. Resultados Inicialmente, foram realizadas oficinas de educação permanente junto aos professorestutores envolvidos na disciplina nos espaços de suas reuniões, para uma aproximação e conhecimento com a metodologia de ensino $\mathrm{ABE}$, visto que essa estratégia ainda não estava sendo utilizada por esses professores. Ao final dessas atividades, também foi planejado o que seria desenvolvido em cada etapa da atividade a ser realizada posteriormente com os alunos. Primeiramente foi encaminhado o material "pré-classe" que permitiu aos alunos o conhecimento sobre a educação e prática interprofissional a partir da leitura do texto: "Educação interprofissional: formação de profissionais de saúde para o trabalho em equipe com foco nos usuários". Para a etapa da "garantia do preparo" os 120 alunos foram divididos em três salas, e dentro dessas, outros pequenos grupos foram montados considerando a organização já existente dentro da disciplina, com a supervisão do professor-tutor de referência. Após essa organização feita dentro das salas em grupos, os alunos responderam individualmente um questionário com dez questões ("teste individual"), relacionadas ao texto previamente fornecido. Passada essa fase cada questão foi discutida dentro de cada grupo, para que assim ocorresse uma discussão não mais de forma individualizada, mas, em grupo e buscando um consenso dentro da equipe ("teste em equipe"). Durante essa etapa foi possível observar uma discussão potente sobre a educação e prática interprofissional com vistas a um trabalho em equipe e colaborativo e sobre a integralidade do cuidado, considerando que a formação em saúde deva também estar pautada em uma efetiva troca de saberes entre os atores envolvidos, dentre outros elementos requeridos, como o reconhecimento da determinação social do processo saúde-doença. Após ampla discussão sobre o tema, cada equipe apresentou sua "apelação", relacionada a uma dada questão selecionada pelo grupo, devido a uma discordância relacionada à resposta. Assim, foi possível a revisão dos conceitos com "feedback" imediato do professor-tutor o que estimulou o aprofundamento das discussões envolvendo o tema. Ao final da atividade os professores-tutores responsáveis pelos grupos, fizeram um fechamento sobre o conteúdo abordado destacando os pontos polêmicos e esclarecendo as dúvidas dos alunos. $\mathrm{Na}$ "aplicação dos conceitos" as equipes se organizaram para visitar/vivenciar algum serviço da Rede de Atenção à Saúde de Botucatu, com o objetivo de observarem como ocorre (ou não) a prática colaborativa e interprofissional no dia-a-dia de um serviço de saúde. Por meio da atividade aqui relatada percebeu-se como potente a experiência em se utilizar a ABE junto a essa disciplina para o aprofundamento sobre o tema da interprofissionalidade, já que essa estratégia pode ser vista como facilitadora do processo de ensino-aprendizagem, por ser um tema bastante teórico e recente em nosso meio. E, também, colaborou para que os conceitos sobre as práticas multiprofissionais, interprofissionais, interdisciplinares e colaborativas fossem discutidas e clarificadas. Desta forma, as discussões realizadas nas equipes permitiram que os alunos refletissem sobre a lógica do trabalho em saúde, onde a colaboração entre os profissionais de saúde, em prol de um efetivo trabalho em equipe, é oportuna para se assegurar uma assistência mais eficaz junto aos pacientes e usuários e percebida como uma estratégia que diminui o distanciamento entre os profissionais da saúde e melhora a qualidade da assistência ofertada às pessoas. CONSIDERAÇÕES FINAIS A ABE apresenta-se como uma metodologia robusta para o ensino, por valorizar a resolução de problemas, ter como focos o diálogo, a negociação e a interação entre os envolvidos, indo ao encontro assim dos preceitos da educação e prática interprofissional.

Descritores: Aprendizagem ativa, Educação superior, Métodos, Ensino. 